\title{
Retraction
}

\section{Retraction of the paper "Forensic entomology and main challenges in Brazil"}

Leonardo Gomes; Cláudio J. Von Zuben

Neotrop. Entomol. 2006; 35(1): 1-11

The Editors of the Neotropical Entomology are retracting the revision paper "Forensic entomology and main challenges in Brazil" by Gomes L. and Von Zuben C. J., published at Neotropical Entomology 2006; 35(1): 1-11 because of plagiarism. The author in charge, L. Gomes, Brazil, has admitted the direct transcription of full sentences and paragraphs and one table of the article "Forensic entomology" by Amendt, J., Krettek, R., Zehner, R., published at Naturwissenschaften 91(2): 5165,2004 , as well as full sentences from the articles "Forensic entomology in Germany" by Amendt, J., Krettek, R., Niess, C., Zehner, R., Bratzke, H., published at Forensic Sci. Int. 113: 309-314, 2000; "Distribution and medical ecology of the blowflies (Diptera: Calliphoridae) of Peru" by Baumgartner, D.L., Greenberg, B., published at Ann. Entomol. Soc. Am 78: 565-587, 1985; "A brief history of forensic entomology" by Benecke, M., published at Forensic. Sci. Int. 120: 2-114, 2001; "Entomology" by Brinkmann, B., published at Int. J. Legal Med. 118 (4): 187, 2004; "The forensic entomologist in the context of the forensic pathologist's role" by Campobasso, C.P., Introna, F., published at Forensic Sci. Int. 120: 132-139, 2001; "Seasonal patterns of arthropods occurring on sheltered and unsheltered pig carcasses in Buenos Aires Province (Argentina)" by Centeno, N., Maldonado, M., Oliva, A., published at Forensic Sci. Int. 126: 63-70, 2002; and The value of PCRRFLP molecular markers for the differentiation of immature stages of two necrophagous flies (Diptera: Calliphoridae) of potential forensic importance" by Thyssen, P.J., Lessinger, A.C., Azeredo-Espin, A.M.L., Linhares, A.X., published at Neotr. Entomol. 34:777-783, 2005, without proper citation, and sends his sincere apologies to all involved. 